\title{
Dor no tornozelo - Um caso de Síndroma Os trigonum
}

Raquel Correia*

\section{RESUMO}

Introdução: O diagnóstico de patologias associadas a dor osteoarticular ou músculo-esquelética na criança e adolescente é um desafio. Dor no tornozelo é uma queixa frequente; porém, o diagnóstico de Síndroma Os trigonum é pouco lembrado na prática médica. Descrição do caso: Relata-se o caso de um rapaz de 18 anos que recorre frequentemente à sua Unidade de Saúde por dor no tornozelo, sem alterações relevantes ao exame físico e na radiografia simples. No entanto, a persistência das queixas e a ocorrência de um traumatismo levam ao pedido de tomografia axial computorizada que revela um Os trigonum.

Comentário: Pretende-se abordar os possíveis diagnósticos diferenciais na presença de dor na região posterior do tornozelo, em particular a síndroma Os trigonum.

Palavras-chave: Dor; Tornozelo; Os trigonum.

\section{INTRODUÇÃO}

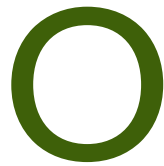

diagnóstico de condições que acarretam dor osteoarticular ou músculo-esquelética na criança e adolescente é um desafio. Estas queixas obrigam a uma abordagem sistematizada para cada faixa etária, de forma a obter uma avaliação mais precisa e orientada para as afeções próprias de cada idade e, caso necessário, aferir quais os exames a serem solicitados, aumentando a probabilidade de um diagnóstico precoce. ${ }^{1}$

Dor no tornozelo é uma queixa frequente; porém, o diagnóstico de síndroma Os trigonumé pouco lembrado na prática médica diária. ${ }^{1}$

A Síndroma Os trigonum, também chamada de Síndroma do Impacto Posterior do Tornozelo, Síndroma de Compressão Talar, Síndroma Compressiva Tibiotalar Posterior ou Bloqueio Posterior do Tornozelo, ${ }^{2}$ é passível de ser tratada com a instituição de terapêutica adequada, ${ }^{1}$ após estabelecimento do diagnóstico.

Relata-se de seguida um caso em que, após avaliação clínica e radiológica, se definiu este diagnóstico, tornando possível a instituição de um tratamento e a obtenção de uma resposta clínica favorável.

\section{DESCRIÇÃO DO CASO CLÍNICO}

Doente do sexo masculino, 18 anos, caucasiano, solteiro, estudante do primeiro ano de música no ensino superior, inserido numa família nuclear em fase $\mathrm{V}$ do ciclo de Duvall, pertencente à classe média de Graffar. Sem antecedentes pessoais ou familiares relevantes. Não pratica desporto regularmente, joga futebol com amigos ocasionalmente.

Este utente apresenta-se numa consulta na Unidade de Saúde Familiar, em janeiro de 2011, com queixas de gonal-

*Médica interna de Medicina Geral e Familiar - USF Novo Cuidar; Fafe; ACES Alto Ave. gia esquerda, sem história de traumatismo e com exame físico sem alterações. Realiza radiografia ao joelho, que também não revela alterações. Em março do mesmo ano mantém a queixa com exame físico, revelando dor à palpação da rótula sem outras alterações relevantes. Realiza tomografia ao joelho, relatada como normal.

Em outubro de 2012 recorre ao serviço de urgência do hospital da área de referência com queixas álgicas a nível do tornozelo e pé esquerdos, sem história de traumatismo conhecida. Realiza radiografias do tornozelo e pé, que não mostram alterações. Tem alta com analgesia.

Recorre novamente a consulta na Unidade de Saúde Familiar em julho de 2013, desta vez com gonalgia bilateral e por manter queixas álgicas no pé esquerdo, sobretudo a nível do calcâneo. No entanto, agora descreve um traumatismo do pé. O exame físico do joelho não mostra alterações, mas o exame físico do pé esquerdo revela dor à mobilização e dor referida ao tendão de Aquiles e região anterior dos maléolos bilateralmente. É medicado com anti-inflamatório e são pedidas radiografias do pé, tornozelo e joelhos, assim como ecografia das partes moles.

No início de setembro de 2013, o doente traz os resultados à consulta, uma vez mais relatados como normais, embora mantenha sintomatologia álgica do tornozelo. É requisitado uma tomografia do tornozelo e pé e mantém a medicação já prescrita.

No final do mesmo mês, o doente apresenta-se na consulta, afirmando sentir-se melhor das queixas. A tomografia demonstra "Os trigonum articulado com possibilidade de apresentar sintomatologia”. Após explicação da situação clínica ao doente, são realizados ensinos acerca da necessidade de exercícios de reforço muscular, utilização de ortótese, repouso, crioterapia e anti-inflamatório nas crises álgicas. 


\section{ACERCA DA SÍNDROMA OSTRIGONUM}

Os trigonum é um osso acessório que se localiza atrás do talus, ao qual está conectado por uma banda fibrosa. Asua presença num ou em ambos os pés é congénita, mas só se torna evidente durante a adolescência, por ausência de fusão com o talus. ${ }^{3}$ Sete a $14 \%$ da população apresenta esta condição. ${ }^{2}$

Frequentemente, as pessoas desconhecem que têm este osso acessório. No entanto, por vezes desenvolvem uma condição dolorosa relacionada com este osso que é referida como Síndroma de Os trigonum. Esta síndroma é habitualmente despertada por um traumatismo ou pela repetida posição do pé em ponta. ${ }^{3}$ É, por isso, uma síndroma muitas vezes descrita em bailarinos, futebolistas, jogadores de voleibol ou corredores de downhill, mas também em pessoas que não praticam qualquer desporto. ${ }^{2}$ Esta posição do pé causa uma lesão em “quebra noz", uma vez que o osso Os trigonumé comprimido entre os ossos do tornozelo e do calcanhar. Os tecidos que o ligam ao talus são colocados sobre pressão e inflamam. ${ }^{3}$

$\mathrm{O}$ doente queixa-se frequentemente de dor crónica na zona posterior do tornozelo habitualmente por sobre-utilização. Rigidez, bloqueio e edema da região posterior do tornozelo também são possíveis. ${ }^{2}$

O diagnóstico baseia-se primeiramente na história clínica e no exame físico que apontam incapacidade para as atividades em flexão plantar do tornozelo e cuja palpação da porção posterior da articulação do tornozelo provoca dor, assim como a manobra de flexão plantar máxima passiva. ${ }^{1}$

Após exame físico, a radiografia ou outros exames de imagem podem ser requisitados (tomografia computorizada, ressonância magnética). A dor nesta localização pode ser complexa, com o diagnóstico diferencial a incluir patologia do tendão de Aquiles, bursite retrocalcânea, patologia do flexor longo do hálux e do peronial, artropatias degenerativas e inflamatórias do calcanhar e do pé posterior, instabilidade do tornozelo, Síndroma do túnel tarsal, lesões osteocondrais talares, Síndroma de Haglund e doença de Sever. ${ }^{2}$

$\mathrm{O}$ tratamento pode ser médico ou cirúrgico. $\mathrm{O}$ tratamento médico passa por repouso e anti-inflamatório não este- roide, como ibuprofeno (na maioria das vezes resolvem a dor); imobilização, por vezes fazendo uso de ortóteses; crioterapia com gelo; fisioterapia; por vezes, é necessário recorrer a corticóides injetáveis. O tratamento cirúrgico raramente é necessário mas, quando necessário (falência do tratamento médico, lesões das estruturas neurovasculares, fratura), tipicamente envolve a remoção do Os trigonum.

\section{COMENTÁRIO}

A dor no tornozelo é uma queixa comum e a Síndroma Os trigonumfaz parte dos diagnósticos diferenciais possíveis, devendo ser lembrada na prática diária, mesmo em doentes não desportistas. ${ }^{1}$

Trata-se de um problema que pode desencadear dor crónica ou frequente quando é passível de tratamento médico e, em raras circunstâncias, cirúrgico.

É importante que o médico de família esteja sensibilizado para esta patologia para que a possa orientar corretamente e tranquilizar o doente.

\section{REFERÊNCIAS BIBLIOGRÁFICAS}

1. Chiereghin A, Martins MR, Gomes CM, Rosa RF, Loduca SM, Chahade WH. Síndrome do impacto posterior do tornozelo: um diagnóstico que deve ser lembrado pelo reumatologista. Relato de dois casos [Posterior ankle impingement syndrome: a diagnosis rheumatologists should not Forget. Two case reports]. Rev Bras Reumatol. 2011;51(3):286-8. Portuguese

2. Song AJ, Del Giudice M, Lazarus ML, Lomasney LM, Demos TC, Dux K. Radiologic case study: Os trigonum syndrome. Orthopedics. 2013;36(1):5,63-8.

3. Consumer Education Committee of the American College of Foot and Ankle Surgeons. Os Trigonum syndrome. ACFAS; 2008. Available from: http://pt.slideshare.net/JimCofano/os-trigonum-syndrome

\section{CONFLITOS DE INTERESSE}

A autora declara não ter conflito de interesses.

\section{ENDEREÇO PARA CORRESPONDÊNCIA}

Raquel Bárbara Mendes Correia

Av. Dr. Leonardo Coimbra, Edifício Idanhas, 1. ${ }^{\circ}$ esquerdo, 4610-105, Felgueiras. E-mail: raquelcorr@gmail.com

Recebido em 04-04-2014

Aceite para publicação em 12-09-2014

\section{ABSTRACT}

\section{ANKLE PAIN - A CASE OF OS TRIGONUM SYNDROME}

Introduction: Diagnosing painful osteoarticular or musculoskeletal conditions in children and teenagers is often a challenge. Ankle pain is a frequent complaint but the Os trigonum syndrome is rarely considered.

Case report: We report the case of an 18 year-old boy who complained of frequent ankle pain. Physical examination and x-ray examination were inconclusive, without remarkable changes. However, the persistence of complaints and the history of an injury led to CT scanning, which revealed an Os trigonum.

Comment: This article presents the differential diagnosis of posterior ankle pain and focuses on the Os trigonum Syndrome.

Key words: Pain; Ankle; Os trigonum. 